D.I.Kinzin, S.A.Levandovskiy

Nosov Magnitogorsk State Technical University

\title{
MANAGEMENT OF ROLLS HANDLING FACILITIES OF LONG PRODUCTS SHOP
}

Abstract. The existing problems of rolls handling facilities, as in the case of PJSC "Magnitogorsk Iron and Steel Works" Long products shop were considered in terms of a proposition to have them solved by means of introduction of an automated information system for accounting and management. A review of literary sources on issues of information technology, management, logistics and organization of rolls handling facilities was performed. The basic provisions of automated information system have been developed, and the issue of rolls handling facilities management on its basis is considered.

Keywords: rolls accounting, rolls handling facility, roll life cycle, automated information system.

\section{Introduction}

The efficiency of rolling mill is largely determined by the quality and culture of operation of the main working tool - mill forming rolls. A wide product mix of rolling mills requires a significant operating fleet of forming rolls and storage areas, which requires high expenditures. At the same time, the consumption of rolls occupies a significant share in the cost of rolling products. The condition and stability of rolls influence on the quality of rolled products and mill's efficiency. It is obvious that improvement of rolls quality, their operation and rational organization of rolls handling facilities will ensure increased productivity, improved quality, and reduce the production costs for long products shop.

The basis for a rational organization of rolls handling facilities is the accounting of mill rolls. Rolls handling facility, the value of which may reach hundreds of millions rubles, requires accurate accounting for the calculation of rolls fleet, the statistical determination of rolls consumption, correct depreciation of rolls to the cost of rolled products, analysis of rolls breakage, etc. At the same time, out-of-date accounting methods do not meet the modern requirements of time and are a drag of development. At the present time, there are more effective information technologies, which open up new opportunities and can become the basis of a competitive advantage.

\section{Existing Problems of Rolls Handling Facilities and Methods for Solving Them}

We shall consider the problems and methods for solving them as in the case of PJSC "Magnitogorsk Iron and Steel Works" Long products shop [1].

Among rolls handling facilities of all rolling shops of PJSC "MMK", the most complex in its structure and number of rolls is the rolls handling facility of long products shop. The total number of grooved rolls is about 2500 for the amount of 500 million rubles. Rolls of flats mills are much more massive and more expensive, but because of the smaller amount of them, it is much easier to control them (for comparison, in RS No. 10 the number of rolls is much smaller than in long products shop). The complexity is not only in quantity, but also in a variety of sizes and materials. There are about 70 different blank rolls used for making the grooves, and considering the rolls pass design, there are about 500 positions that differ significantly from each other.

The range of rolls consumption per ton of rolled products may differ significantly depending on the rolled profile [2]. In long products shop the share of costs for rolls in 2006 amounted to about $15 \%$ of the total costs of production area, which is worth paying attention. If we calculate the consumption of rolls on specific rolling profiles, the product mix in long products shop has about five hundred profiles, we shall get a very heterogeneous structure. The rolls consumption during rolling of different profiles can differ by tens of times. However, only the average cost price is calculated, despite the fact that different profiles can bring different profits, and probably some sort of 
products is unprofitable. The calculation of costs in terms of distribution of costs for rolls can be performed much more accurately. At least, it is quite possible to distribute these expenses by groups of profiles, since the costs for rolls are inherently direct and variable [3].

To solve the task, it is necessary to have accurate information about how many rolls are consumed and to what types of products. The knowledge of rolls consumption is also necessary for the development of a rational budget for rolls for the next year of rolling mills operation.

The lack of necessary information makes it impossible to solve other pressing problems. In particular, it is impossible to analyze the causes of rolls breakage, and, consequently, develop justified measures to reduce them. It is extremely difficult to carry out experimental work on changing the pass design and material of rolls, since there are a lot of such experiments and they last for many months, so the results can be obtained only in the form of statistical indicators. The lack of such information forces us to draw conclusions based on indirect and subjective sources.

An important task is the effective combination of grooves on rolls. A large number of rolls are cut into different grooves. If this is not done, the consumption of the rolls will be reduced, but the total number of rolls that are in operation will increase several fold. There is every indication of the optimization problem.

The great complexity of long products shop rolls handling facility makes it difficult to manage and generates mistakes when working with it, which lead to a decrease in production and quality of rolled products.

\section{Development of Basic AIS Regulations for Rolls Handling Facility Control}

The basis for solving the described problems can become an automated information system (AIS) for accounting and management of long products shop rolls handling facility.

The current stage of development is characterized by the transition to an information society. No organization can carry out its activities without information. In the normal functioning of an organization, in terms of its management all the employees, from a simple worker or an employee to the director need a variety of information. At the same time, information processes are not the end in themselves; their aim is the ultimate control of material flows and their interaction. In this connection, the solution of rational use problems of modern and promising methods and means of processing information in practical activities acquires paramount importance. Domestic and foreign experience convincingly proves that the development of metallurgical enterprises, the solution of quality problems and competitiveness of steel products in the world market require radical improvement of systems for collecting, storing, processing, transferring and using the information [4]. This is the only way to significantly increase the effectiveness of professional activity. The application of new information technologies makes it necessary to carry out a new evaluation of the effectiveness of an enterprise's activity [5]. Information technologies are also the basis for success of the application of logistics and new approaches to organization of business processes.

However, the most important advantage of an automated accounting system is that the management can at any time observe an objective picture of their business and immediately analyze it. A PC will show the current situation and the process history. It makes it possible to control all aspects of the activity and see what has slipped of our attention before [6].

There is a need for system that will take into account the specifics of mills' operation and their product mix. At the same time, the work on information input should be evenly distributed among employees who are the carriers of such information. Such a system should become the information foundation of management activity, and not be limited only to accounting. The commissioning of such a system is aimed at reducing the costs of a production area, improving electronic document management, continuous evaluation and analysis of performance, improving the manageability of the workshop. Such AIS are created using database technology, which is well developed and widely used. To create such systems, high-performance computing equipment is not required.

Each roll experiences various events from the moment of purchase to the moment of disposal. Each roll can have its own unique history of such events. Despite the diversity, the "life path" of 
any roll can be put in a general scheme. In the block diagram of possible events (Fig. 1), rectangles indicate the events themselves, and rhombuses - the stages of decision making.

Then the main principle that lets us know the history of each roll will be the mandatory reflection of all the events in AIS.

AIS of rolls handling facility management will allow to evaluate a number of key indicators that reflect the system's efficiency.

These are the following recommended indicators:

- rolls consumption per unit of time (current stock of rolls);

- insurance stock of rolls;

- number of rolls in operation;

- number of rolls in warehouses;

- fleet of rolls (total number of rolls);

- rolls consumption per 1 ton of rolled steel;

- rolls resource;

- coefficient of a roll use;

- illiquid stock of rolls;

- turnover of rolls.

All the above indicators should be calculated automatically and also automatically presented in the form of monthly and annual reports. In addition, reports should include checksums that will show the reliability of the information provided, for example, the amount of rolled steel according to AIS data and the actual amount for the same period.

Along with automatically generated reports, the system should allow the creation of a report on the user's request to obtain the necessary information in a convenient form.

AIS of accounting and management of rolls handling facility of long products shop opens up new opportunities for reducing production costs.

\section{Ways to Reduce Costs and the Economic Effect with Introduction of AIS}

One way to reduce costs of mill rolls is to increase the coefficient of their application. Rolls never reach their resource up to $100 \%$. It has to do with the following reasons:

- rolls breakage;

- errors during grooving;

- combination of grooves on a roll body;

- a roll is sent to grooving with unused passes.

It is hardly possible to completely eliminate these reasons, but it is possible to reduce their impact due to a more accurate accounting system.

In particular, the availability of a digital database for rolls calibration will eliminate the need to have paper drawings. Since calibration is constantly changing for various reasons, there are many versions of drawings that can not be tracked. This will also increase labor productivity due to elimination of many unnecessary activities.

The roll pass design department, as the developer of drawings, will have to keep the database up to date, which can not be done with a lot of paper copies. In addition, the database could contain rolling modes for operators and rollermen. The existence of a single, correct, up to date and available for everybody version of rolls pass design will contribute to order and reduce errors.

The goal of combining different passes on rolls is to reduce the fleet of rolls and number of rolls change, because one and the same rolls can roll different profiles. However, monthly rolling campaigns differ from each other in the composition of profiles and volume of orders. It means that not all grooves are used in this campaign, and leaving them to the next one is not rational. It is not possible to refuse to combine the passes due to the fact that this will lead to an increase in the rolls fleet several times. But it is possible to make it more rational having full information about the grooves application. 


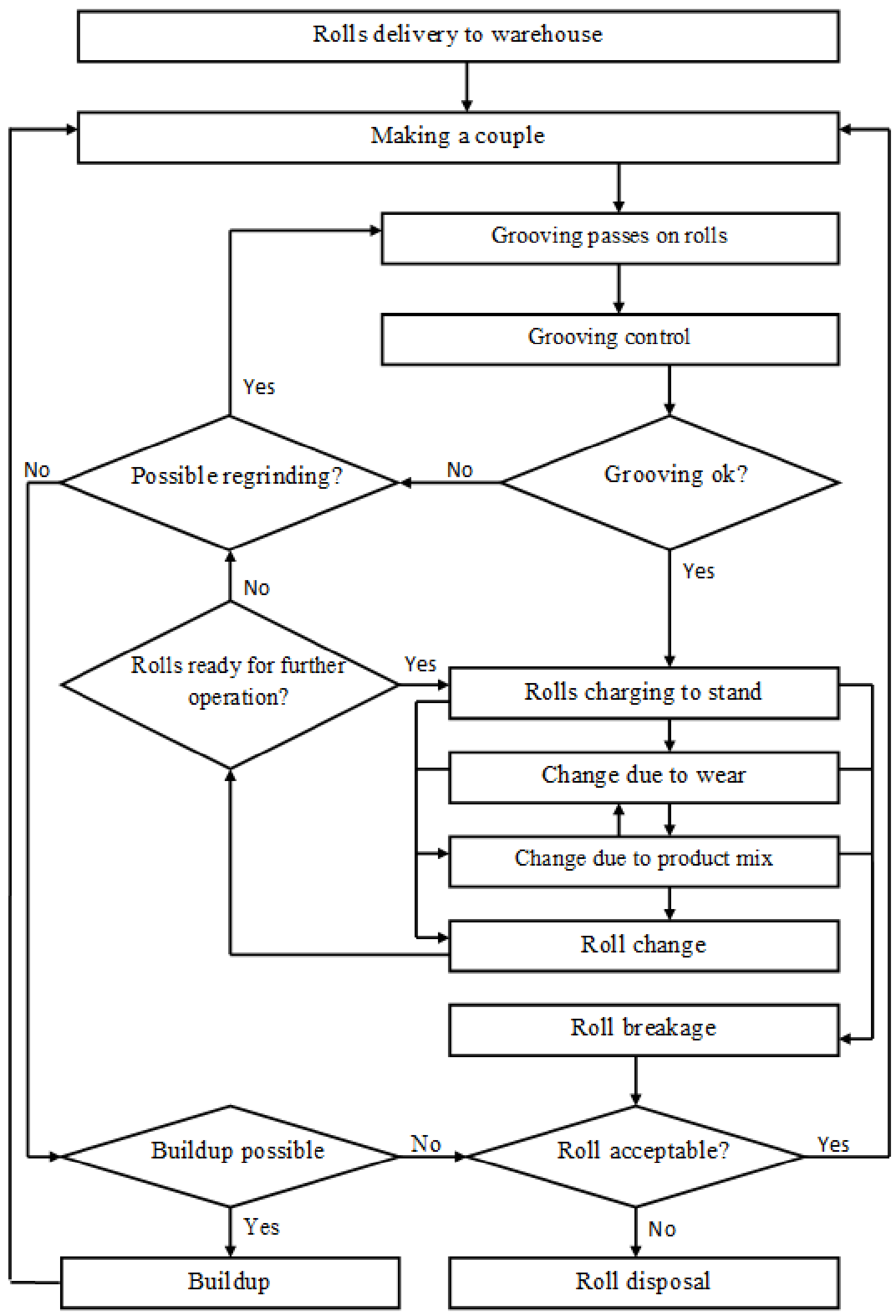

Fig 1. Event flow chart 
Another, perhaps the most significant, way of reducing costs is in the field of controlling the stock of rolls [7]. Using scientific methods of inventory management allows us to identify hidden internal resources of the enterprise. Managing the production stock - means that you are always able to meet the requirements of production. If the inventory management is carried out taking into account this requirement, then its implementation is possible only on the basis of a certain level of reserves. The more stocks, the easier it is to meet the demand for them. But this condition distracts significant amount of circulating assets into stocks and reduces their turnover, i.e. reduces the efficiency of using the means of production. But a small number of them leads to losses. The methods for regulating reserves tend to be more effective if there is more information on demand available. The use of recommendations of the theory of inventory management requires a scientific approach to studying the patterns of demand. In our case, while we are talking about controlling the stock of rolls, the customer is a rolling mill. The information on rolls consumption should be concentrated in AIS, which will serve as the basis for determining economically justified norms of a marginal level of rolls stock. A distinctive feature of the rolls handling facility of PJSC "MMK" long products shop is that the insurance stock of rolls considerably exceeds the current stock. It has to do with a wide product mix and high inertia of the production process, the continuity of which is extremely important. Therefore, the greatest effect can be expected from reduction of the insurance stock. When making a stock of rolls, we are still guided by the principle - the more, the better. And at the same time we refer to Soviet norms [8], which are clearly outdated. It is also not acceptable to apply these norms because modern mills are equipped with rolls with much higher resource. The experience acquired during operation of new mills indicates that the available stock of rolls is not optimal. The real resistance of grooves turned out to be higher than it was assumed in the construction of mills.

A particular interest is the illiquid stock of rolls - these are rolls with grooved calibers, but they are not used. It has to do with the fact that the workshop's product mix contains very rare rolling profiles that can be rolled once in few years. As a rule, the volume of orders for such products does not exceed 120 tons. Therefore, rolls service life for these profiles can be hundreds of years. From the point of view of functional and cost analysis, it is not rational to have rolls with service life exceeding the service life of a rolling mill. Moreover, a few years is quite a long period during which many things can change (the consumer will disappear or its technology will change and the need for this profile will vanish). In view of the above, it would be more rational to regrinding such rolls to other profiles. Another way is to groove passes of rare profiles on the rolls that have ended a part of their performance potential, and not preserve their resource for many years. There may be other solutions. In any case, it is necessary to consider each specific case individually, and without full information it is impossible.

\section{Conclusion}

The analysis of that insignificant information available today makes it possible to expect that after the implementation of AIS a fleet of rolls can be reduced. This is possible due to a clearer definition of grooves stability and rolls consumption, and therefore a smaller re-evaluation of the risk of formation of rolls deficit [9], reduction in the number of errors and a more rational combination of grooves.

In the modern world the information in terms of its importance is not inferior to other resources and information technologies is the most dynamically developing sphere of life $[10,11,12]$. It is Obvious that a large enterprise has no future without the development of this sphere.

We have illustrated how an automated control system, quite simple in the development and operation, can affect the production process $[13,14]$. With the right approach to the matter, information systems can provide a serious competitive advantage. 


\section{References}

1. F.S.Dubinsky, A.I.Chubayev, M.A.Sosedkova. Automated system for planning and monitoring the rolls fleet, Proceedings of the Sixth Congress of Rollers (Lipetsk, October 18-21, 2005), Moscow 1 (2005) 508-511.

2. A.V.Tretyakov. Rolls of roughing, section, and sheet mills, Moscow, SP INTERMET ENGINEERING, 1999.

3. G.D.Feigin. The organization of rolls handling facility, Moscow, Metallurgizdat, 1961.

4. M.G.Lapusta, CEO's record book, Ed. 2-nd, corrected. and additional, Moscow, INFRA-M, 1998.

5. A.Gaponenko. Information technologies of an enterprise management. Ways to increase their effectiveness, Director's consultant, 21 (2004) 16-20.

6. N.A.Spirina. Information systems in metallurgy, Textbook for universities, Ekaterinburg, Ural State Technical University, UPI, 2001.

7. A.M.Zevakov, V.V.Petrov. Logistics of industrial and commodity stocks, Textbook, SPb., 2002.

8. Technological instruction TI 101-P-SPSH-198-87. Production of hot-rolled profiled sections on mill 250-1. Magnitogorsk, 1988.

9. Linders R.Michael, Phiron E.Harold. Supply and Inventory Management. Logistics, Translated from English, St. Petersburg, Polygon, 1999.

10. A.B.Moller, A.A.Zaitsev, O.N.Tulupov. Model of setting up a bar mill with a matrix description of shaping in passes of simple form, Steel in Translation, 29(10) (1999) 59-63.

11. O.N.Tulupov, A.B.Moller. Simulation of bar rolling: Experience at Nosov Magnitogorsk State Technical University, Steel in Translation. 44(4) (2014) 280-288.

12. D.V.Nazarov, E.A.Zakharov, S.V.Denisov, A.B.Moller, K.A.Zavyalov. Assessing channel rolling on a 450 mill, Steel in Translation. 39(10) (2009) 901-905.

13. A.B.Moller, O.N.Tulupov, S.A.Fedoseev. Improvement of surface quality of rolled section steel for springs manufacturing, Journal of Chemical Technology and Metallurgy, 52(4) (2017) 647-654.

14. S.A.Levandovsky, O.N.Tulupov, A.B.Moller, D.I.Kinzin, Improvement of the slitting process for rebar rolling to increase the material yield and rolling mill 370 utilization at PJSC MMK. CIS Iron and Steel Review. 15(2) (2018) 18-23. 